\title{
Pertumbuhan Earning per Share, Price to Book Value dan Price Earning Ratio Sebagai Dasar Keputusan Stock Split
}

\author{
Djoni Budiardjo dan Joshe Hana Hapsari \\ Fakultas Ekonomi, Universitas Airlangga \\ Jl. Airlangga No.4-6, Surabaya 60286
}

\begin{abstract}
The objective of this research is to examine the effect of earning per share, price to book value and price earning ratio on firm's stock split. According to signaling hypothesis, stock split decision can be proxies with the growth of earning per share, while trading range hypothesis can be proxies with the price to book value and price earning ratio. The population of this research is manufacturing firms that did stock split between years 2003 to 2008. The samples consist of 40 firms, and the analysis using logistic regression model. The result is that the growth of earning per share did not have a significant effect to firm stock split decision, while price to book value and price earning ratio did have significant effect to the prediction of firms in doing stock split.
\end{abstract}

Keywords: signaling hypothesis, stock split decision, trading range hypothesis, growth of earning per share, price to book value, and price earning ratio

\section{PENDAHULUAN}

Corporate action merupakan aktivitas emiten yang berpengaruh terhadap jumlah saham beredar maupun berpengaruh terhadap harga saham pasar. Corporate action paling sering dilakukan oleh perusahaan-perusahaan emiten, karena strategi ini paling menarik perhatian pihak-pihak yang terkait pasar modal khususnya para pemegang saham. Selain itu corporate action dilakukan emiten dalam rangka memenuhi tujuan-tujuan tertentu, seperti misalnya bertujuan untuk meningkatkan modal perusahaan, meningkatkan likuiditas perdagangan saham maupun tujuan-tujuan lainnya.

Salah satu jenis corporate action adalah pemecahan saham (stock split). Pemecahan saham biasanya dilakukan oleh perusahaan yang harga sahamnya memiliki harga pasar yang tinggi, dan dalam kondisi yang baik. Pemecahan saham ini dilakukan untuk kapitalisasi yang mempengaruhi jumlah saham yang beredar, nilai pari, earning per share, dan harga saham atau price earning ratio, Mayo (1993:266). Pemecahan saham berarti perusahaan membuat harga saham menjadi lebih bisa dijangkau oleh lebih banyak pemegang saham. Motivasi perusahaan untuk melakukan pemecahan saham biasanya adalah untuk meningkatkan likuiditas saham-sahamnya. Dengan besarnya likuiditas dari saham-saham ini akan memperbesar distribusi sahamsahamnya, sehingga diharapkan nantinya akan menaikan harga sahamnya di pasar. Selain itu adanya pengumuman stock split dianggap merupakan sinyal positif bagi para investor akan kinerja keuangan perusahaan, karena stock split dilakukan dengan biaya dan kinerja keuangan perusahaan ini diharapkan akan terus membaik di masa depan (Baker \& Powell, 1993).

Dari uraian di atas maka tidak sembarang perusahaan akan melakukan pemecahan saham. Motivasi perusahaan yang melakukan pemecahan saham adalah perusahaan yang kinerja keuangannya baik, selain itu perusahaan ini juga memiliki harga atau nilai saham yang tinggi pula. Baik tidaknya kinerja keuangan suatu perusahaan bisa dinilai dari laba bersih setelah pajak (earning after tax), laba per lembar saham (earning per share). Kinerja perusahaan akan dianggap baik jika EAT terus meningkat yang mengindikasikan bahwa perusahaan mampu memaksimalkan penjualannya di atas biaya-biaya yang dikeluarkan. Jika perusahaan memiliki nilai EAT yang tinggi, maka perusahaan akan mampu memberikan EPS yang tinggi di tiap lembar sahamnya, hal ini akan membuat harga pasar saham perusahaan juga akan meningkat. Maka dalam kondisi seperti ini perusahaan akan melakukan stock split agar saham-sahamnya lebih likuid. Indikator lain yang perlu diperhatikan adalah tingkat pertumbuhan earning per share atau EPS Growth, yaitu pertumbuhan EPS yang akan tercermin pada peningkatan laba bersih (EAT), Return to Equity (ROE) dan book value saham. Hal ini akan memberikan sinyal bahwa kinerja perusahaan sedang baik, dan akan mendorong harga pasar saham perusahaan menjadi semakin tinggi, maka dalam kondisi seperti ini 
perusahaan bisa melakukan stock split. Hal ini sesuai dengan Signaling Theory di mana perusahaan harus meningkatkan kinerja perusahaanya sebelum melakukan stock split agar dapat memberikan sinyal kepada para investor bahwa prospek perusahaan akan terus baik di masa datang.

Tinggi rendahnya harga atau nilai saham suatu perusahaan bisa dilihat melalui rasio harga saham terhadap nilai buku (Book Value per Share), dan rasio harga saham terhadap laba bersih (Price Earning Ratio). Tingginya nilai PBV mencerminkan nilai buku dan likuiditas saham yang tinggi pula, sedangakan tingginya nilai PER mencerminkan tingginya nilai EPS. Hal ini akan membuat harga pasar saham perusahaan menjadi semakin mahal dan perusahaan akan melakukan stock split agar sahamsahamnya lebih terjangkau dan menjadi semakin likuid. Hal ini sesuai dengan Trading Range Theory di mana perusahaan dengan harga saham yang tinggi akan melakukan stock split agar saham-sahamnya lebih likuid dan dimiliki lebih banyak investor.

Pendapat dan perilaku para investor mungkin saja ditentukan dengan melihat pertumbuhan EPS dan rasio harga saham seperti yang telah dijelaskan sebelumnya, namun beberapa penelitian mendapatkan hasil yang berbeda-beda atas tanggapan investor tentang perusahaan yang melakukan pemecahan saham. Ada perilaku investor yang mengikuti kenaikan earning sebelum pemecahan yang menurut pandangan mereka lebih bersifat sementara. Ada yang menganggap bahwa kenaikan earning sebelum pemecahan merupakan hal yang permanen. Tindakan stock split juga sering dikatakan sebagai 'kosmetik' yang digunakan perusahaan untuk memberikan kesan seakan-akan kondisi perusahaan sedang baik dan akan terus membaik di masa depan. Ternyata banyak yang mempengaruhi sebuah perusahaan untuk melakukan stock split, dan perilaku investor dalam melihat tiap variabel yang menentukan suatu perusahaan untuk melakukan dan tidak melakukan stock split juga berbeda. Berdasarkan uraian di atas, maka penelitian ini dilakukan untuk melihat pengaruh Earning Per Share, Price to Book Value dan Price Earning Ratio terhadap keputusan suatu perusahaan untuk melakukan pemecahan saham.

\section{KAJIAN TEORITIS}

\section{Motif Perusahaan Melakukan Stock Splits}

Banyak yang beranggapan bahwa stock split hanya merupakan 'kosmetik' bagi perusahaan agar investor menganggap bahwa kinerja keuangan perusahaan saat ini sedang baik dan memiliki prospek yang baik di masa depan. Hal ini sesuai dengan hasil penelitian Baker \& Powell (1993), bahwa sebagian besar manajer mengakui bahwa stock split merupakan 'kosmetik' yang tidak berpengaruh pada kekayaan pemegang saham.

Menurut Brigham \& Houston (1998: 96-97), perusahaan melakukan stock split untuk memberikan isyarat bahwa prospek perusahaan tampak baik, selain itu ketika harga sahamnya jauh di atas kisaran harga (range) normal. Setiap pemegang saham akan memiliki lebih banyak lembar saham, tetapi memiliki nilai lebih kecil di tiap lembarnya. Kekayaan pemegang saham sama seperti sebelumnya, akan tetapi saat harga per lembar saham perusahaan nantinya bergerak naik kembali, maka kekayaan pemegang saham akan menjadi lebih baik.

Motif perusahaan melakukan stock split adalah memberi sinyal adanya optimisme manajerial pada prospek perusahaan yang baik, membuat harga saham ke dalam range harga yang diminati investor, sehingga nantinya memperbesar likuiditas saham perusahaan (Baker \& Powell, 1993). Motif untuk memberikan sinyal bahwa kinerja keuangan dan prospek perusahaan baik, disebut dengan Signaling hypothesis, sedangkan motif untuk menurunkan harga saham ke dalam range harga yang diminati investor disebut juga dengan Trading Range hypothesis.

\section{Signaling Hypothesis}

Signaling hypothesis menjelaskan bahwa dengan melakukan stock split, perusahaan berarti ingin menyampaikan informasi kepada investor tentang prospek perusahaan di masa depan. Menurut Baker \& Powell (1993), stock splits adalah sinyal informatif mengenai prospek perusahaan yang baik di masa depan. Informasi yang asimetri antara perusahaan dan investor, akan mendorong perusahaan melakukan stock split.

Menurut Asquith et al. (1989), ada dua tipe informasi yang ingin disampaikan perusahaan melalui stock split, pertama adalah informasi tentang kinerja laba di masa depan dan yang kedua adalah informasi tentang pertumbuhan laba sebelum split. Dalam penelitiannya dinyatakan bahwa saat diumumkannya stock split, ekspektasi investor akan peningkatan laba perusahaan pada masa sebelum stock split adalah permanen. Dengan demikian, investor menganggap perusahaan yang melakukan stock split adalah perusahaan yang memiliki kemampuan menghasilkan laba yang terus meningkat.

Menurut Lakonishok \& Lev dalam Baker \& Powell (1993), sinyal yang disampaikan melalui stock split adalah tentang stabilitas pertumbuhan laba, 
prospek naiknya dividen kas di masa depan atau keduanya. Stock split dilakukan setelah laba dan tren EPS perusahaan mengalami peningkatan. Hal ini berarti bahwa proses signaling berhubungan dengan kondisi laba bersih (EAT) dan laba per saham (EPS) yang dicerminkan dalam pertumbuhan laba per saham (EPS growth). Dengan melakukan stock split, berarti perusahaan ingin menyampaikan bahwa besarnya laba dan pertumbuhan EPS sedang dalam kondisi baik dan mengalami peningkatan, baik sebelum stock split maupun sesudah stock split.

\section{Trading Range Hypothesis}

Trading range menurut Hirt (1999:692) adalah "the high and low spread of prices that a stock normally sells within". Trading Range hypothesis menjelaskan bahwa perusahaan melakukan stock split agar harga sahamnya berada pada range harga yang diminati pasar, sehingga diharapkan menjadi lebih lebih likuid. Menurut Baker \& Powell (1993), motif utama melakukan stock split adalah untuk menurunkan harga saham perusahaan ke dalam range harga yang diminati pasar, meningkatkan likuiditas dan memperluas jangkauan kepemilikan. Distribusi lembar saham ke lebih banyak investor akan memperbesar likuiditas saham perusahaan, memperbesar proporsi kepemilikan saham ke lebih banyak individu dan mencegah pengambilalihan kontrol perusahaan (unfriendly takeover).

Menurut penelitian Mayo (1993), stock split dilakukan saat harga pasar saham perusahaan sangat tinggi. Tinggi rendahnya harga saham dapat dilihat dari tingginya nilai rasio price to book value (PBV) dan price earning ratio (PER).

Semakin tinggi kemampuan perusahaan dalam menghasilkan laba dan apresiasi pasar terhadap saham-sahamnya, maka semakin tinggi pula harga sahamnya. Walaupun harga saham yang tinggi ini mencerminkan kinerja keuangan perusahaan yang baik, namun saham-saham dengan PER dan PBV yang tinggi kurang diminati banyak investor individu. Ketika rasio P/E (PER) perusahaan di atas normal, harga saham perusahaan akan menjadi sangat tinggi sehingga hanya beberapa orang saja yang mampu membeli dalam round-lot yang terdiri atas 100 lembar saham (Brigham \& Houston, 1998). Jika hal ini terjadi, maka nilai pasar perusahaan kecil karena sahamnya hanya dimiliki beberapa investor saja dan likuiditasnya berkurang. Menurut Baker \& Gallagher (1986), “... high-priced stocks are not as popular with individual investors and these stocks tend to have a more restricted market". Hal ini akan menyebabkan distribusi kepemilikan saham perusahaan tidak luas kepada investor individu, tetapi hanya pada pasar tertentu. Transaksi saham yang sedikit menyebabkan turunnya likuiditas saham di bursa, maka dengan melakukan stock split harga pasar saham bisa turun ke dalam range yang diminati pasar dan terjangkau oleh lebih banyak investor.

\section{Kerangka Pemikiran}

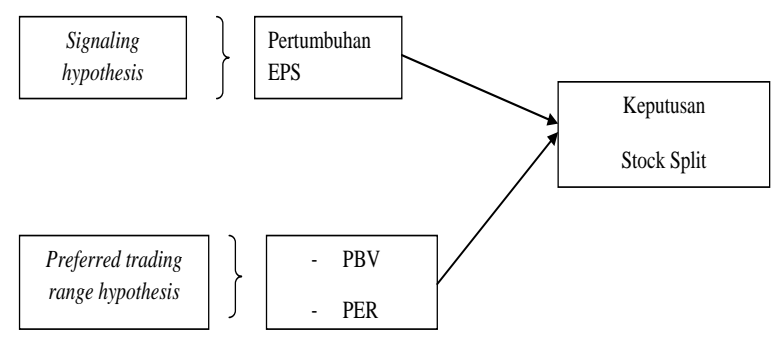

\section{Hipotesis}

Sesuai dengan latar belakang masalah, dan landasan teori yang dikemukakan sebelumnya, maka hipotesis yang digunakan dalam penelitian ini adalah: H1: pertumbuhan earning per share berpengaruh positif terhadap keputusan perusahaan untuk melakukan stock split.

H2: price to book value berpengaruh positif terhadap keputusan perusahaan untuk melakukan stock split.

H3: price earning ratio berpengaruh positif terhadap keputusan perusahaan untuk melakukan stock split.

\section{METODE PENELITIAN}

\section{Pendekatan Penelitian}

Pendekatan penelitian ini menggunakan alat analisis statistik regresi logistik. Menurut Ghozali (2006:71), regresi logistik digunakan untuk menguji apakah probabilitas terjadinya variabel terikat dapat diprediksi dengan variabel bebasnya. Dalam penelitian ini akan diuji seberapa besar probabilitas keputusan perusahaan untuk melakukan stock split yang dapat diprediksi dengan pertumbuhan Earning Per Share, Price Earning ratio dan Price to Book Value.

\section{Model Analisis}

Penelitian ini ingin melihat apakah semua variabel bebas di atas berpengaruh signifikan terhadap keputusan perusahaan yaitu untuk melakukan stock split atau tidak melakukan stock split, dimana model 
penelitian ini menggunakan model regresi logistik dengan persamaan sebagai berikut:

$$
Y_{i t}={\underset{e}{i t}}_{\beta_{0}}+\beta_{1} G(E P S)_{i(t-1)}+\beta_{2} P B V_{i(t-1)}+\beta_{3} P E R_{i(t-l)}+
$$

Dimana:

$$
\begin{aligned}
Y_{i t}= & \text { keputusan perusahaan pada tahun } \mathrm{t} . \\
& \text { Nilai } 1 \text { bila stock split, nilai } 0 \text { bila tidak } \\
& \text { stock split. } \\
G(E P S)_{i(\mathrm{t}-1)}= & \text { pertumbuhan EPS saham i pada tahun } \\
& \mathrm{t}-1 \\
P B V_{i(\mathrm{t}-1)}= & \text { rasio harga saham i terhadap nilai buku } \\
& \text { pada tahun } \mathrm{t}-1 \\
P E R_{i(\mathrm{t}-\mathrm{l})}= & \text { rasio harga saham i terhadap laba bersih } \\
& \text { pada tahun } \mathrm{t}-1 \\
\beta_{0}= & \text { intercept. } \\
\beta_{1}-\beta_{3} \beta_{1}= & \text { koefisien regresi. } \\
e_{i(\mathrm{t}-1)}= & \text { variabel pengganggu saham i pada } \\
& \text { tahun } \mathrm{t}
\end{aligned}
$$

\section{Definisi Operasional}

1. Variabel tergantung $(\mathrm{Y})$ dalam regresi logistik yaitu perusahaan yang mengambil keputusan stock split (1) adalah perusahaan yang melakukan pengumuman pemecahan saham. Sedangkan perusahaan yang tidak memutuskan untuk stock split adalah perusahaan dalam industri yang sama dan besaran yang sama dengan perusahaan yang melakukan stock split, akan tetapi tidak melakukan pengumuman pemecahan saham (0).

2. Variabel-variabel bebas (X) dalam regresi logistik yaitu:

a) Pertumbuhan Earning Per Share (EPS Gowth) Rasio ini menunjukan kemampuan perusahaan dalam meningkatkan EPS dari tahun sebelumnya dan dapat dirumuskan sebagai berikut:

$$
g=\frac{E P S_{(t)}-E P S_{(t-1)}}{E P S_{(t-1)}}
$$

Atau dapat pula dihitung menggunakan rumus;

$$
\left(\frac{R O E_{1}}{R O E_{0}}\right) \times\left(\frac{B V_{1}}{B V_{0}}\right)-1.0
$$

b) Rasio Harga Saham terhadap Nilai Buku (PBV)

Rasio harga saham terhadap nilai buku adalah ekuitas pemegang saham dikurangi nilai pari saham preferen yang beredar pada akhir tahun t lalu dibagi dengan jumlah saham beredar pada akhir tahun t. PBV dapat dirumuskan sebagai berikut:

$$
P B V=\frac{\text { Harga saham }}{\text { Nilai buku saham }}
$$

c) Rasio Harga Saham terhadap Laba Bersih (PER)

Rasio harga saham akhir tahun t terhadap earning per share akhir tahun t. PER dapat dirumuskan sebagai berikut:

$$
P E R=\frac{\text { Harga } \text { saham }}{\text { EPS }}
$$

\section{HASIL DAN PEMBAHASAN}

\section{Hasil Regresi Logistik}

Analisis yang digunakan dalam penelitian ini adalah analisis regresi logistik regresi berganda dengan keputusan perusahaan melakukan stock split (Y) sebagai variabel tergantung. Variabel-variabel

\begin{tabular}{|c|c|c|c|c|c|c|}
\hline \multirow[t]{2}{*}{ Variabel } & \multirow{2}{*}{$\begin{array}{l}\text { Koefisien } \\
\text { Regresi }\end{array}$} & \multirow{2}{*}{$\begin{array}{l}\text { Tingkat } \\
\text { Signifikansi }\end{array}$} & \multirow{2}{*}{$\begin{array}{l}\text { Odd } \\
\text { Ratio }\end{array}$} & \multicolumn{2}{|c|}{$\begin{array}{c}\text { Interval } \\
\text { Kepercayaan } \\
\end{array}$} & \multirow[t]{2}{*}{ Keterangan } \\
\hline & & & & Bawah & Atas & \\
\hline Konstanta & $-2,860$ & 0,016 & 0,057 & & & $\begin{array}{l}\text { Signifikan } \\
\text { Tidak }\end{array}$ \\
\hline GEPS (X1) & 0,470 & 0,399 & 1,600 & 0,537 & 4,770 & Signifikan \\
\hline PER (X2) & 0,133 & 0,043 & 1,143 & 1,004 & 1,300 & Signifikan \\
\hline PBV (X3) & 2,083 & 0,041 & 8,030 & 1,087 & 59,297 & Signifikan \\
\hline \multicolumn{4}{|c|}{ Chi Square Hosmer \& Lemeshow } & \multicolumn{3}{|c|}{3,609} \\
\hline \multicolumn{4}{|c|}{ Signifikansi } & \multicolumn{3}{|c|}{0,891} \\
\hline \multicolumn{4}{|c|}{ Nagelkerke R Square } & \multicolumn{3}{|c|}{0,691} \\
\hline \multicolumn{4}{|c|}{ Cox \& Snell R Square } & \multicolumn{3}{|c|}{0,518} \\
\hline & \multicolumn{3}{|c|}{77,5} \\
\hline \multicolumn{4}{|c|}{ Overall Percentage Classification } & \multicolumn{2}{|c|}{ Stock Split } & $\begin{array}{l}\text { Tdk. Stock } \\
\text { Split }\end{array}$ \\
\hline \multicolumn{3}{|l|}{ GEPS (X1) } & & \multicolumn{2}{|c|}{0,1036} & $-0,4006$ \\
\hline \multicolumn{3}{|l|}{$\operatorname{PER}(\mathrm{X} 2)$} & & \multicolumn{2}{|c|}{52,0525} & $-2,7045$ \\
\hline \multicolumn{3}{|l|}{ PBV (X3) } & & \multicolumn{2}{|c|}{3,5465} & 0,4965 \\
\hline
\end{tabular}
bebasnya adalah pertumbuhan Earning Per Share (X1), Price to Book Value (X2), dan Price Earning Ratio (X3).

Metode enter digunakan sebagai metode analisis regresi logistik, merupakan salah satu metode regresi secara umum, yang digunakan untuk menganalisis apakah variabel-variabel bebas mempunyai pengaruh atau tidak terhadap variabel tergantung dengan syarat variabel tergantung berskala pengukuran non metrik dan variabel-varibel bebas berskala pengukuran metrik atau non metric (Ghozali, 2006). Perhitungan regresi logistik berganda dalam penelitian ini dilakukan dengan menggunakan SPSS versi 11.0 (for windows).

Tabel 1. Hasil Uji Regresi Logistik Berganda Pertumbuhan EPS, PBV dan PER Sebagai Dasar Keputusan Stock Split Perusahaan Manufaktur Periode Januari 2003-Juni 2008.

Berdasarkan Tabel 1 diperoleh persamaan regresi logistik sebagai berikut:

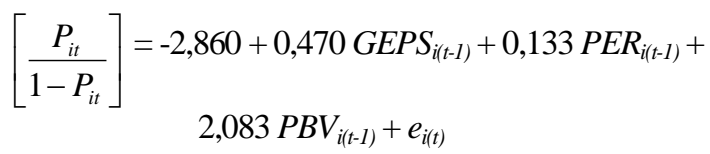


atau probabilitas keputusan perusahaan untuk melakukan stock split adalah sebesar:

$P=\frac{1}{1+e^{-(-2,860+0,470 G E P S+0,133 P E R+2,083 P B V)}}$

Pengertian dari persamaan regresi logistik di atas adalah bahwa probabilitas keputusan perusahaan untuk stock split dan tidak stock split dapat dihitung dengan persamaan tersebut. Angka probabilitas berkisar antara 0 sampai dengan 1 . Jika hasil persamaan mendekati 1, berarti probabilitas keputusan perusahaan untuk stock split akan lebih besar. Jika hasil persamaan mendekati angka 0 , berarti probabilitas keputusan perusahaan untuk tidak stock split akan lebih besar. Probabilitas kedua keputusan tersebut dipengaruhi oleh variabel-variabel yang telah ditentukan dalam penelitian ini.

Adapun pengertian nilai-nilai tiap koefisien regresi logistik adalah sebagai berikut:

a. Konstanta ( $(\beta)$ memiliki koefisien regresi logistik sebesar -2,860. Artinya jika variabel bebas lain sama dengan nol (0), maka kemungkinan perusahaan untuk melakukan stock split akan turun sebesar 2,860 satuan nilai. Tanda negatif pada koefisien menunjukkan hubungan yang berlawanan antara konstanta $(\beta o)$ dan $Y$.

b. G EPS (X1) memiliki koefisien regresi logistik sebesar 0,470. Artinya jika pertumbuhan Earning Per Share naik 1\%, maka kemungkinan perusahaan untuk melakukan stock split akan naik sebesar 0,470 satuan nilai, dengan asumsi variabel-variabel bebas lainnya dalam keadaan konstan. Akan tetapi, hasil penelitian menunjukkan bahwa pertumbuhan earning per share memiliki hubungan positif tidak signifikan terhadap keputusan stock split perusahaan.

c. PER (X2) memiliki koefisien regresi logistik sebesar 0,133. Artinya jika Price Earning Ratio naik $1 \%$, maka kemungkinan perusahaan untuk melakukan stock split akan naik sebesar 0,133 satuan nilai, dengan asumsi variabel-variabel bebas lainnya dalam keadaan konstan. Tanda positif pada koefisien menunjukkan hubungan yang searah antara X2 dengan Y. Berarti semakin tinggi rasio PER, maka semakin besar kemungkinan perusahaan untuk melakukan stock split.

d. PBV (X3) memiliki koefisien regresi logistik sebesar 2,083. Artinya jika Price to Book Value naik $1 \%$, maka kemungkinan perusahaan untuk melakukan stock split akan naik sebesar 2,083 satuan nilai, dengan asumsi variabel-variabel bebas lainnya dalam keadaan konstan. Tanda positif pada koefisien menunjukkan hubungan yang searah antara X3 dengan Y. Berarti semakin tinggi rasio PBV, maka semakin besar kemungkinan perusahaan untuk melakukan stock split.

\section{Pengaruh Pertumbuhan Earning Per Share Terhadap Keputusan Stock Split}

Secara parsial, penelitian ini menemukan bahwa pertumbuhan Earning Per Share mempunyai hubungan yang positif tidak signifikan terhadap keputusan perusahaan untuk melakukan stock split. Pengaruh positif yang tidak signifikan variabel pertumbuhan Earning Per Share terhadap keputusan stock split menunjukkan bahwa adanya kecenderungan perusahaan untuk melakukan stock split setelah ada pertumbuhan earning per share. Pengaruh positif tersebut sesuai dengan hasil penelitian Lakonishok \& Lev dalam Baker \& Powell (1993), bahwa stock split dilakukan setelah ada peningkatan tren laba dan EPS. Keputusan untuk stock split setelah adanya kenaikan pertumbuhan EPS ini terkait dengan Signaling Hypothesis. Dengan melakukan stock split, perusahaan berusaha memberikan dua jenis informasi kepada investor. Yang pertama adalah prospek kinerja keuangan perusahaan di masa datang, dan yang ke dua adalah adanya pertumbuhan laba perusahaan sebelum melakukan stock split. Hal ini sesuai dengan hasil penelitian Asquith et al. (1989) yang menunjukkan adanya pertumbuhan laba empat tahun sebelum stock split. Pertumbuhan EPS dapat mencerminkan pertumbuhan laba perusahaan.

Ketidaksignifikanan pertumbuhan earning per share terhadap keputusan stock split, menunjukkan bahwa ternyata dalam penelitian ini pertumbuhan EPS ternyata tidak selalu menjadi motivasi perusahaan untuk melakukan atau tidak melakukan stock split. Hal ini dikarenakan pertumbuhan EPS perusahaan yang stock split tidak lebih baik daripada perusahaan yang tidak stock split. Pertumbuhan EPS perusahaan khususnya dua tahun sebelum stock split, ternyata banyak yang memiliki angka yang negatif. Tanda negatif ini berarti bahwa pertumbuhan EPS perusahaan selama dua tahun sebelum stock split, mengalami penurunan. Pertumbuhan EPS perusahaan yang tidak melakukan stock split ternyata tidak seluruhnya memiliki pertumbuhan yang negatif.

Dari hasil uji regresi logistik juga terlihat bahwa mean pertumbuhan EPS perusahaan yang stock split memiliki selisih yang kecil dengan mean pertumbuhan EPS perusahaan yang tidak melakukan stok split. Hal ini menunjukkan bahwa pertumbuhan EPS kedua kelompok perusahaan tersebut tidak jauh berbeda. Pernyataan ini sesuai dengan hasil penelitian Iramani (2005), bahwa pertumbuhan earning after tax dan pertumbuhan earning per share perusahaan yang stock split tidak lebih tinggi dibandingkan perusahaan yang tidak stock split. 


\section{Pengaruh Price to Book Value Terhadap Keputusan Stock Split}

Secara parsial, penelitian ini menemukan bahwa Price to Book Value mempunyai hubungan positif yang signifikan terhadap keputusan perusahaan untuk melakukan stock split. Hubungan positif menunjukkan bahwa perusahaan-perusahaan ini melakukan stock split karena PBV yang dimiliki mendekati atau lebih besar dari satu (1). Hal ini berarti PBV yang dimiliki termasuk tinggi karena harga saham mereka dinilai pasar lebih tinggi dibanding nilai bukunya. Sesuai dengan hasil penelitian Alteza (2008), bahwa perusahaan dengan PBV yang tinggi memiliki kemungkinan besar untuk stock split.

Hubungan positif PBV dengan stock split terkait dengan Trading Range Theory, di mana perusahaan dengan PBV tinggi akan melakukan stock split. Stock split dilakukan agar saham-sahamnya lebih diminati investor, karena saham dengan PBV yang tinggi akan memiliki harga saham yang tinggi pula. Sesuai dengan pernyataan Baker \& Gallagher (1986), bahwa dengan menurunkan harga per saham melalui stock split akan menjangkau lebih banyak investor, terutama bagi investor kecil yang lebih memilih membeli dalam round-lot. Selain itu, diversifikasi kepemilikan saham bisa dicapai dengan nilai yang tidak berubah.

Kesignifikanan Price to Book Value dengan keputusan stock split ditunjukkan dengan tingginya nilai PBV yang dimiliki perusahaan-perusahaan yang melakukan stock split. Hampir seluruhnya bernilai positif jauh di atas angka satu (1), dibandingkan dengan nilai PBV perusahaan-perusahaan tidak stock split yang banyak bertanda negatif. Ini berarti bahwa harga saham selama satu tahun sebelum stock split dinilai pasar lebih tinggi daripada nilai bukunya. Dari tabel uji regresi logistik juga menunjukkan mean PBV perusahaan stock split lebih besar dibandingkan dengan mean PBV perusahaan yang tidak stock split. Hal ini berarti bahwa rata-rata PBV perusahaan yang stock split lebih baik daripada yang tidak stock split. Hasil penelitian ini sesuai dengan hasil penelitian yang dilakukan Iramani (2005), bahwa PBV perusahaan yang stock split lebih tinggi dibandingkan dengan yang tidak stock split.

\section{Pengaruh Price Earning Ratio Terhadap Keputus- an Stock Split}

Secara parsial, penelitian ini menemukan bahwa Price Earning Ratio mempunyai hubungan positif yang signifikan terhadap keputusan perusahaan untuk melakukan stock split. Hubungan positif antara PER dengan keputusan untuk stock split ini menunjukkan bahwa perusahaan akan melakukan stock split jika nilai PER yang dimiliki cukup besar, yang artinya harga sahamnya jauh lebih tinggi dari earning per share. Tingginya PER melambangkan tingginya apresiasi pasar terhadap kemampuan perusahaan dalam menghasilkan laba, Darmadji (2004:140). Rasio PER merupakan indikator tinggi rendahnya harga saham di mata investor, sehingga semakin tinggi nilai PER semakin tinggi pula harga saham di mata investor. Keputusan stock split karena tingginya nilai PER ini terkait dengan Trading Range Hypothesis. Pemecahan saham ini dilakukan agar harga saham bisa menjadi lebih murah di mata investor dan dapat memperbesar ownership base saham perusahaan. Motif ini sama dengan motif saat perusahaan melakukan stock split karena rasio PBV yang tinggi.

Kesignifikanan hubungan antara Price to Earning Ratio dengan keputusan stock split, dikarenakan nilai PER perusahaan-perusahaan yang melakukan stock split menunjukkan angka-angka yang tinggi dan sebagian besar menunjukkan tanda positif. Artinya selama satu tahun sebelum stock split, pasar mengapresiasi kemampuan perusahaan dalam menghasilkan laba sehingga tercermin dalam PER yang tinggi. Hal ini sesuai dengan penelitian Asquith et al. (1989) bahwa harga saham perusahaan meningkat dua tahun sebelum perusahaan itu melakukan stock split. Dari tabel hasil uji regresi logistik ditunjukkan bahwa mean PER perusahaan yang stock split lebih besar daripada yang tidak stock split. Berarti bahwa nilai PER perusahaan yang melakukan stock split lebih tinggi daripada yang tidak melakukan stock split. Hal ini sesuai dengan penelitian Alteza (2008), bahwa nilai PER perusahaan yang stock split lebih besar daripada yang tidak melakukan stock split.

\section{Dasar Utama Keputusan Stock Split}

Dari hasil penelitian didapat bahwa Price to Book Value dan Price Earning Ratio memiliki hubungan yang positif signifikan terhadap keputusan stock split, hal ini berarti bahwa Trading Range Hypothesis menjadi dasar utama bagi perusahaanperusahaan dalam penelitian ini untuk melakukan stock split. Trading Range Hypothesis menandakan bahwa perusahaan-perusahaan dalam penelitian ini menginginkan agar saham-sahamnya lebih likuid dan lebih terjangkau ke lebih banyak investor.

Pertumbuhan Earning Per Share dalam penelitian ini memiliki hubungan yang positif tidak signifikan terhadap keputusan stock split, hal ini berarti bahwa Signaling Hypothesis tidak menjadi dasar utama bagi perusahaan-perusahaan dalam pene- 
litian ini untuk melakukan stock split. Pertumbuhan EPS satu tahun sebelum stock split menunjukkan pertumbuhan yang negatif, sehingga tujuan utama melakukan stock split tidak untuk penyampaian sinyal akan baiknya kinerja keuangan kepada investor.

Earning Per Share selama satu tahun sebelum stock split sebagian besar menunjukkan rasio yang tinggi dan angka yang positif walaupun mengalami penurunan dari tahun sebelumnya. Perusahaan mengharapkan dapat menyampaikan hal ini kepada investor melalui stock split, walaupun trading range yang menjadi dasar utamanya. Dengan demikian stock split dijadikan 'kosmetik' oleh perusahaanperusahaan ini dalam hal penyampaian sinyal kinerja keuangan.

\section{KESIMPULAN}

Berdasarkan hasil analisis statistik dan pembahasan, maka dapat ditarik kesimpulan bahwa:

1. Variabel pertumbuhan Earning Per Share mempunyai pengaruh positif tidak signifikan terhadap keputusan perusahaan untuk melakukan stock split.

2. Variabel Price to Book Value mempunyai pengaruh positif signifikan terhadap keputusan perusahaan untuk melakukan stock split. Hal ini berarti bahwa perusahaan dengan rasio PBV yang semakin tinggi maka semakin tinggi pula probabilitas perusahaan untuk melakukan stock split.

3. Variabel Price Earning Ratio mempunyai pengaruh positif signifikan terhadap keputusan perusahaan untuk melakukan stock split. Hal ini berarti bahwa perusahaan dengan PER yang semakin tinggi maka semakin tinggi pula probabilitas perusahaan untuk melakukan stock split.

4. Trading Range Hypothesis menjadi motif yang lebih dominan bagi perusahaan-perusahaan dalam penelitian ini dalam melakukan stock split. Selain itu, stock split dapat dijadikan 'kosmetik' untuk tujuan penyampaian sinyal kinerja keuangan perusahaan.

\section{DAFTAR PUSTAKA}

Alteza, Muniya. Januari 2008. "Kinerja Keuangan dan Harga Saham sebagai Dasar Keputusan Stock Split", Manajemen Usahawan Indonesia, No. 1, hal. 14-19.

Anonim. 2003-2008. Jakarta Stock Exchange Statistics, Bursa Efek Indonesia, Jakarta.
Anonim. 2003-2007. Indonesia Capital Market Directory, Institute for Economics and Financial Research, Jakarta.

Asquith, Paul. July 1989. "Earnings and Stock Splits", The Accounting Review, Vol. LXIV, No. 3, page 387-403.

Baker, H.K. \& Gallagher. 1980. "Management's View of Stock Splits", Financial Management (pre-1986), Summer, page 73-77.

Baker, H.K. \& Powell. 1993. "Further Evidence on Managerial Motives for Stock Splits", Quarterly Journal of Business and Economics, Summer, page 20-31.

Belkoui, Ahmed Riahi. 1998. Financial Analysis \& the Predictability of Important Economic Events, Quorum, USA.

Brigham, Eugene F. 1995. Fundamentals of Financial Management, Seventh Edition, Forth Worth: The Dryden Press.

Brigham, Eugene F. \& Joel F. Houston. 1998. Fundamentals of Financial Management, Eighth Edition, Ohio: The Dryden Press.

Brigham, Eugene F. \& Fred J. Weston. 1990. DasarDasar Manajemen Keuangan, Jakarta: Erlangga.

Darmadji. 2004. Pasar Modal di Indonesia, Jakarta: Salemba Empat.

Ghozali, Imam. 2006. Analisis Multivariate Lanjutan dengan Program SPSS, Semarang: Badan Penerbit Universitas Diponegoro.

Hirt, Geoffrey A. 1999. Fundamentals of Investment Management, Sixth Edition, Boston: McGraw Hill.

Iramani, Muazaroh. April 2006. "Analisis Kinerja Keuangan, Kemahalan Saham, dan Likuiditas pada Pemecahan Saham", Ventura, Vol. 9, No. 1, hal. 45-59.

Mayo, Hebert B. 1993. Investments, Ohio: The Dryden Press.

Mishkin, Frederic S. \& Stanley G. Eakins. 2003. Financial Markets and Institutions, Fourth Edition, Boston: Pearson.

Radcliffe, Robert C. 1990. Investments: Concepts, Analysis, Strategy, Third Edition, Glenview: Scott, Foresman and Company.

Sharpe, William F., Gordon J. Alexander \& Jeffery V. Bailey. 1997. Investasi, Edisi Bahasa Indonesia, Jilid 2, Jakarta: PT. Prenhalindo. 